\title{
Methodology: Reaching the most vulnerable adolescent girls
}

Population Council

Follow this and additional works at: https://knowledgecommons.popcouncil.org/departments_sbsr-pgy

Part of the Demography, Population, and Ecology Commons, Family, Life Course, and Society Commons, International Public Health Commons, and the Women's Health Commons How does access to this work benefit you? Let us know!

\section{Recommended Citation}

"Methodology: Reaching the most vulnerable adolescent girls," AGEP Brief. Lusaka: Population Council, 2016. 


\section{METHODOLOGY: REACHING THE MOST VULNERABLE ADOLESCENT GIRLS}

The Adolescent Girls Empowerment Program (AGEP) is a program for girls ages 10-19 in rural and urban Zambia that aims to find the best ways to improve their social, health, and economic resources. The program involves over 10,000 girls participating in weekly girls' group meetings, receiving health vouchers and opening savings accounts. Over 5,000 girls, unmarried at baseline, are enrolled in a randomized, controlled trial and are being followed over four years-including the two years of the program and two years after. This brief describes the methods used to reach the most vulnerable girls in AGEP.

\section{REDUCE VULNERABILITIES, EXPAND OPPORTUNITIES}

The objective of AGEP is to provide vulnerable adolescent girls with needed social, health, and economic assets that they can draw upon to overcome their vulnerabilities and expand their opportunities.

As a component of the AGEP evaluation, a household census was conducted in 2013 in the areas where the program was to be implemented. The census revealed that a significant percentage of adolescent girls aged 10-19 contend with multiple levels of socioeconomic vulnerability that include-but are not limited togeographic remoteness, social isolation, living without parents, living in low-income households, and not attending school. By some measures, urban and rural girls are about equally vulnerable. For instance, data from the household census within the AGEP study areas indicates that among girls aged 10-19 in the 10 AGEP program areas:

- One-quarter are currently out of school

- $62 \%$ have mothers with only primary school education or less

- $8 \%$ are currently married

- One-third have at least one parent who has died

- Nearly one in five have two living parents, but do not live with either

- One-half do not have electricity

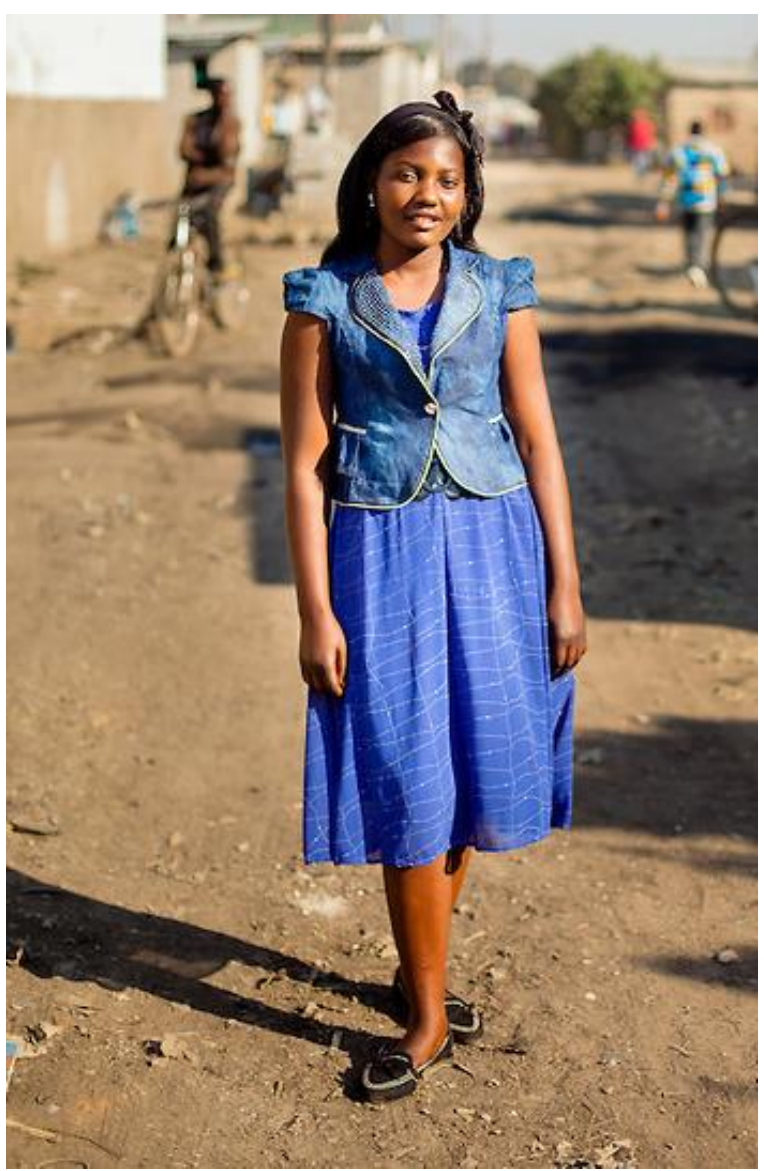

By other measures, rural girls are more vulnerable than urban girls:

- nearly half of rural girls live without access to safe water, compared with one-in-ten urban girls

- three-quarters of rural girls live without access to improved sanitation, compared with nearly half of urban girls

- $57 \%$ of rural girls live an hour or more away from secondary school, compared with $26 \%$ of urban girls

- $42 \%$ of rural girls live an hour or more away from a health center, compared with only $9 \%$ of urban girls 


\section{Girls are isolated from key places}

Average number of minutes girls live away from four key places

(\% of girls who live an hour or more away from key locations)

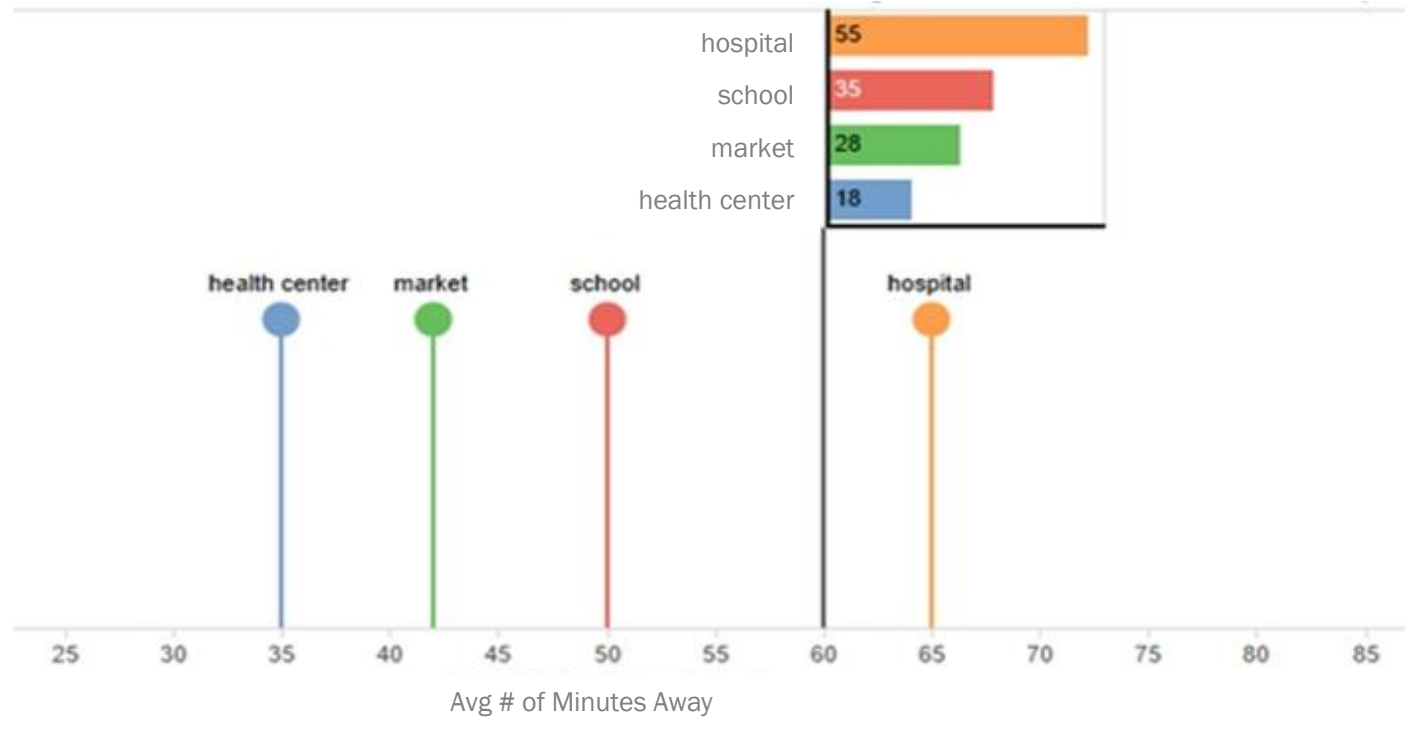

\section{Developing a vulnerability indicator}

To be cost-effective, programs that are intended to benefit vulnerable young people need ways to identify them. For AGEP, a relatively simple measure of being behind grade-for-age was collected and used as a method for identifying and selecting the most vulnerable adolescent girls.

One important consideration in identifying and selecting vulnerable girls for participation in AGEP was not to over-represent older girls or girls who have already experienced any of the outcomes to be measured (e.g., having dropped out of school, being orphaned, becoming pregnant, or getting married). This consideration is important from both programmatic and research perspectives because a core objective of the program was to prevent such adverse outcomes. It was therefore preferable to reach a significant proportion of girls who were at risk of adverse adolescent life-course outcomes.

To do this, "behind school grade-for-age" was used as an indicator for vulnerability. Many children fall behind early in the school-going process because of late entry, repetition of grades, and temporary withdrawal- the result of some degree of personal and/or household vulnerability. A body of literature exists that documents negative relationships between lagging behind in school, and education, economic, and health outcomes.
To empirically develop the vulnerability measure, an ordinary least squares (OLS) regression was estimated with the number of grades behind for age as the dependent variable; independent variables in the regression model included age, not in school, ever married, and having at least one child. The estimated residual of the regression was then used to represent vulnerability, with higher residuals indicating higher vulnerability. Conceptually, the residual of the regression represents the accumulated vulnerability that girls have experienced throughout their lives, independent of the other variables in the regression, as manifested through their impact on their educational progress. If this measure is effective at capturing vulnerability, it should be positively associated with a range of other adverse conditions and experiences for adolescents.

Based on the results of the OLS regression, adolescent girls in each site were ordered by their estimated levels of vulnerability and 16,600 of the most vulnerable were selected to receive invitations to participate in the program with the anticipation that at least 10,000 would actually do so. The benefit of this approach is that it helps to reach girls who are vulnerable but who have not already experienced other adverse outcomes; this will help us maximize the potential of prevention efforts. The measure also 
is able to identify girls who are lagging behind in school but who live in circumstances or within households that otherwise appear favorable, perhaps due to factors difficult to measure, such as parenting practices or household investment in children.

\section{Evaluating indicator validity}

To assess whether this measure of vulnerability is associated with other adverse outcomes and evaluate the validity of the indicator of vulnerability, we conducted a logistic multivariable analysis and calculated the odds ratios (ORs) using the household census data.

The results of the logistic regression are presented in Table 1.

In the logistic analysis, the outcome variable was coded as being two or more grades behind versus being no more than one grade behind. This definition allowed for the fact that age is not always reported accurately and that children whose birthdays fall shortly before the cutoff date for school enrollment may be more likely to appear to be behind one grade than children whose birthdays fall shortly after the cutoff date.

As shown in Table 1, almost all of adolescent characteristics and adverse conditions are strongly associated with being behind in school. For instance, as girls age, they are significantly more likely to have accumulated missed years of schooling; with each additional year the odds of falling behind in school increase by $28 \%$ in urban areas and 32\% in rural areas. Falling behind in school is also directly associated with having already left school, with at least two girls who have already left school having fallen behind compared to every one girl who has not left school.

Table 1 Characteristics associated with adolescents being behind grade-for-age, a urban and rural Zambia

\begin{tabular}{|c|c|c|c|c|}
\hline & \multicolumn{2}{|c|}{ Urban } & \multicolumn{2}{|c|}{ Rural } \\
\hline Adolescent characteristics & OR (SE) & p-value & OR (SE) & p-value \\
\hline Age $^{b}$ & $1.28(.01)$ & $* * *$ & $1.32(.01)$ & $* * *$ \\
\hline Not attending school & $2.13(.08)$ & $* * *$ & $2.50(.17)$ & $* * *$ \\
\hline Ever married & $1.28(.13)$ & $* * *$ & $1.23(.18)$ & \\
\hline Has at least one child & $2.27(.18)$ & $* * *$ & $1.22(.15)$ & $\dagger$ \\
\hline Physically disabled & $3.13(.60)$ & $* * *$ & $1.13(.42)$ & \\
\hline \multicolumn{5}{|l|}{ Parental characteristics } \\
\hline Father not alive & $1.07(.05)$ & & $0.79(.06)$ & $* *$ \\
\hline Mother not alive & $1.18(.06)$ & $* * *$ & $1.04(.09)$ & \\
\hline Father has primary schooling or less & $1.47(.06)$ & $* * *$ & $1.59(.09)$ & $* * *$ \\
\hline Mother has primary schooling or less & $1.97(.07)$ & $* * * *$ & $1.94(.12)$ & $* * *$ \\
\hline Father alive but not living in household & $1.31(.07)$ & $* * *$ & $1.01(.07)$ & \\
\hline Mother alive but not living in household & $1.20(.07)$ & $* * *$ & $1.37(.12)$ & $* * *$ \\
\hline \multicolumn{5}{|l|}{ Household characteristics } \\
\hline Female head of household & $0.77(.03)$ & $* * *$ & $0.85(.06)$ & * \\
\hline Girl has younger siblings in household & $1.25(.05)$ & $* * *$ & $1.27(.09)$ & $* * *$ \\
\hline Lack of savings or assets for emergencies & $1.22(.04)$ & $* * *$ & $1.15(.06)$ & $* *$ \\
\hline Lack of electricity & $2.01(.07)$ & $* * *$ & $1.34(.07)$ & $* * *$ \\
\hline Lack of safe drinking water & $1.18(.05)$ & $* * *$ & $1.38(.07)$ & $* * *$ \\
\hline Lack of improved sanitation & $1.30(.04)$ & $* * *$ & $1.15(.07)$ & * \\
\hline Time to nearest secondary schoolb & $3.78(.73)$ & $* * *$ & $2.77(.46)$ & $* * *$ \\
\hline Time to nearest market ${ }^{b, c}$ & - & & $1.48(.29)$ & * \\
\hline
\end{tabular}

†Significant at $p<0.10 ; * p<0.05 ; * * p<.01 ; * * * p<.001$.

NOTE: Logistic regression analysis conducted from household census data; includes covariates for study sites (not shown).

a Measured as being two or more grades behind for age.

b Indicator measured as a continuous variable; for time to secondary school and markets, OR interpreted as the change in odds across from the shortest to the longest time.

c Information collected for rural areas only. 


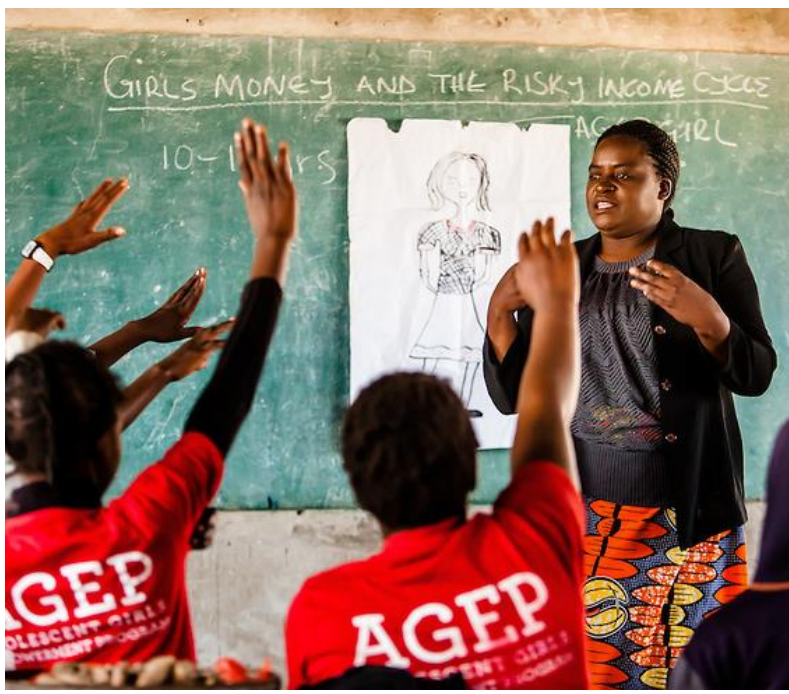

Other characteristics of the girls are also significantly associated with falling behind in urban areas, including being married, having a child, and being physically disabled. Being physically disabled does not seem to affect falling behind in school for rural areas, but this may be due to the small number of cases observed (126 out of more than 11,000 girls).

Similarly strong associations between falling behind in school and parental and household characteristics are documented in Table 1. One potential interpretation of the findings on paternal death is that when the household is led by a female (whether a spouse or other female), girls are less likely to fall behind in school, potentially due to a more positive enabling environment and control over resources in the household for girls' education. Parents' education levels are also critical determining factors in the progress of adolescent girls.

For instance, girls whose mothers have primary schooling or less have nearly twice the odds of being behind grade-for-age than children with mothers having higher levels of schooling. A significant but less powerful effect is observed for paternal education. Whether the adolescent girl has younger siblings, whether the household lacks savings in cases of emergency, and the housing conditions in which adolescents live are also associated with age-appropriate progression through school. Finally, the distance to secondary schools is also a critical determining factor in school progress with the implication that the longer the time it takes to reach school the greater the odds of falling behind.

\section{CONCLUSION}

The analysis presented here indicates that the relatively simple method of demonstrating vulnerability used in AGEP-that is, being behind grade for age-is strongly associated with an array of other indicators of vulnerability. This measure is a good way to more readily identify girls who are at risk of negative outcomes when recruiting for programs to improve their lives.

This program is funded by UKaid from the Department for International Development.

\section{CONTACT INFORMATION}

For more information about AGEP:

call: +260 211295925

email: agep@popcouncil.org

visit: http://www.popcouncil.org/research/

adolescent-girls-empowerment-program
Population Council

Plot \#3670 No. 4 Mwaleshi Road

Olympic Park

Lusaka, Zambia 10101 